\title{
Eyelid retraction is not a pathognomonic sign of Machado-Joseph disease in the context of spinocerebellar ataxias
}

Retração palpebral não é um sinal patognomônico da doença de Machado-Joseph no contexto das ataxias espinocerebelares

José Luiz Pedroso, Paulo Victor Sgobbi de Souza, Wladimir Bocca Vieira de Rezende Pinto, Marcus Vinicius Cristino Albuquerque, Orlando G. P. Barsottini

We describe three patients with spinocerebellar ataxia (SCA) and marked eyelid retraction: A 33-year-old woman with ataxia, pyramidal signs and eyelid retraction; genetic test confirmed SCA1 (Figure A). A 41-year-old man with ataxia, ophthalmoplegia, neuropathy and eyelid retraction; genetic test confirmed SCA2 (Figure B). A 68-year-old man with ataxia, neuropathy, nystagmus and eyelid retraction; genetic test confirmed SCA3 or Machado-Joseph disease (MJD) (Figure C).
Patients with SCA, other than MJD, in special SCA1, SCA2 and SCA10, may rarely present with eyelid retraction $^{1,2,3}$. This neurological feature presumes a more widespread degenerative process involving the midbrain ${ }^{3}$. SCA patients with eyelid retraction and negative genetic test for MJD should be tested for other SCA subtypes, particularly SCA1, SCA2 and SCA10 $0^{2,3}$.
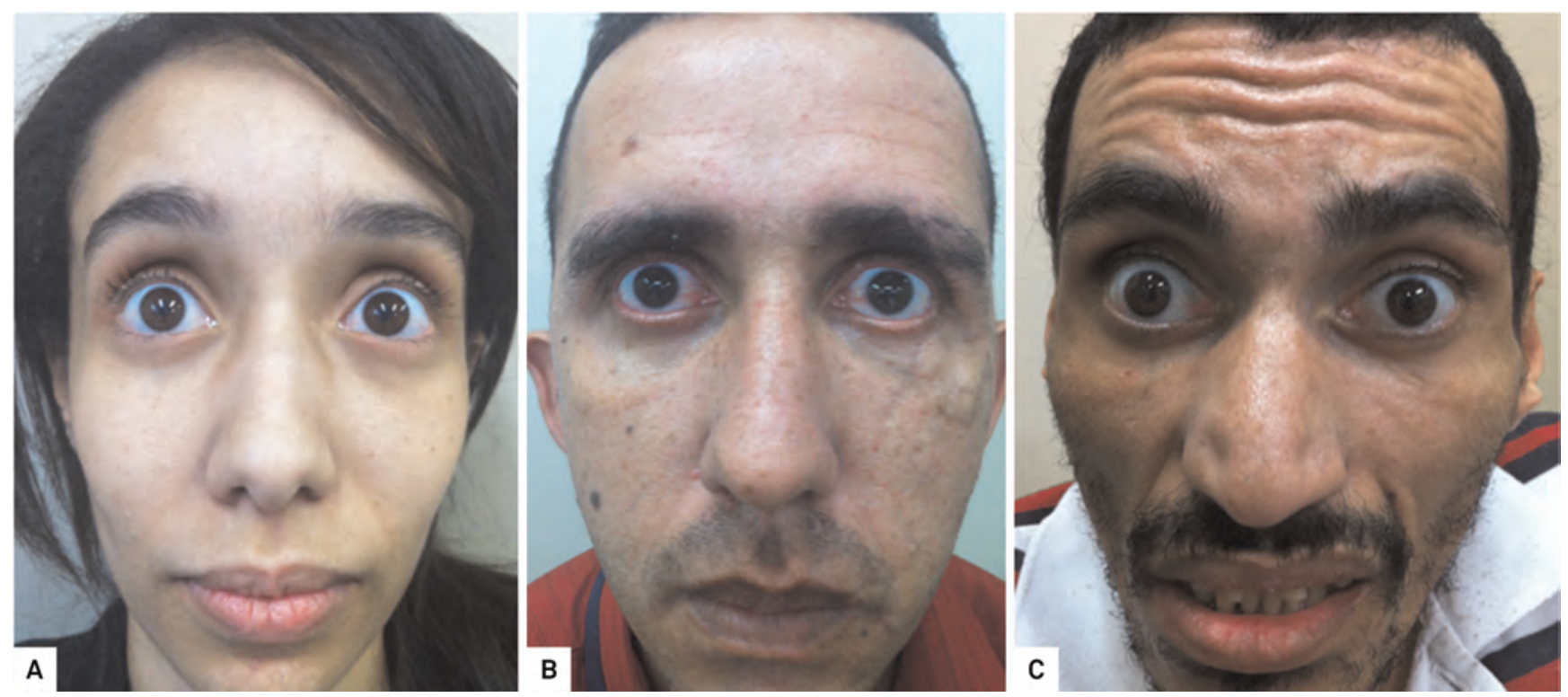

Figure. All three patients, SCA1 (A), SCA2 (B) and SCA3 (C) have widening of the eyelid opening with white parts of the sclera appearing above and below the limbus, characterizing eyelid retraction or Collier's sign.

Departamento de Neurologia, Unidade Ataxia, Universidade Federal de São Paulo, Sao Paulo SP, Brazil.

Correspondence: José Luiz Pedroso; Rua Botucatu, 740; 04023-900 Sao Paulo SP - Brasil. E-mail: jlpedroso.neuro@gmail.com

Conflict of interest: There is no conflict of interest to declare.

Received 23 October 2013; Received in final form 28 November 2013; Accepted 18 December 2013. 
1. Jardim LB, Pereira ML, Silveira I, Ferro A, Sequeiros J, Giugliani R. Neurologic findings in Machado-Joseph disease: relation with disease duration, subtypes, and (CAG)n. Arch Neurol 2001;58:899-904.

2. Pedroso JL. Diagnosis at a first glance? "Bulging eyes" as a clue for a more accurate diagnosis in spinocerebellar ataxias. Arq Neuropsiquiatr 2013;71:421-422.
3.

Moro A, Munhoz RP, Arruda WO, Raskin S, Teive HA. Clinical relevance of "bulging eyes" for the differential diagnosis of spinocerebellar ataxias. Arq Neuropsiquiatr 2013;71:428-430. 